\title{
A Realidade Política e o Ensino Jurídico
}

\author{
José Eduardo Faria \\ Professor Associado do Departamento de \\ Filosofia e Teoria Geral do Direito da \\ Faculdade de Direito da USP
}

\begin{abstract}
RESUMO: O ensino jurídico no Brasil, do modo como se encontra tradicionalmente organizado e praticado, passou a sofrer grandes críticas ao longo destes últimos anos. Este artigo identifica e avalia essas críticas, examinando como os conceitos de educação, sociedade e Estado normalmente são definidos pelos professores e transmitidos aos alunos. $O$ texto também analisa o atual universo conceitual nas faculdades de direito e suas matrizes ideológicas, as transformaçōes verificadas na função social dos juristas e, por fim, as relações entre os fenômenos jurídicos e os fenômenos sociais, por um lado, e entre o direito positivo e as construções científicas, por outro.
\end{abstract}

\begin{abstract}
The forms in which the teaching of law is at present conducted in Brazil are being incresingly, and contested. This article aims to suggest the reasons for this contestation, on the basis of an analysis of the following: the mode in which the concepts of education, society and the state are defined and transmitted to the students; the transformations which have occurred in the social function of jurists; and, in addition, the relations between juridical and social phenomena, and, on the other'side, between positive law and theoretical models. This analysis, oriented by a conception of the social functions of law as a mechanism for the dispersal of contradictions, is followed by a proposal in favour of a reduction in the emphasis given to jurisprudence, and the development of an organic, flexible and interdisciplinary approach to the teaching of law, given that, in present-day societies, the State is obliged to practice a diversification of juridical forms and of the normative and institutional structure in which they operate.
\end{abstract}

"Durante o aprendizado nas faculdades de direito somos levados a assumir uma atitude meramente passiva quanto ao mundo em que nos cerca. $O$ nosso papel enquanto futuros advogados, enquanto futuros profissionais do direito

José Eduardo Faria é professor-adjunto do Depto. de Filosofia e Teoria Geral do Direito da USP. Este artigo é o resumo de dois ítens de um relatório apresentado à Comissão de Ensino da FD-USP sobre a reorganização do curso de graduação em direito. 
sequer é mencionado, resumindo-se nossos cursos à interpretação e absorção pura e simples das normas vigentes. É a priorização da dogmática que impede uma maior conscientização do estudante quanto à sua missão social, na medida em que a pesquisa científica voltada para temas jurídicos não recebe qualquer estímulo".

Essa crítica ao ensino jurídico hoje vigente no País foi feita há poucos anos por um grupo de jovens que, ao diplomar-se na Faculdade de Direito da Universidade Federal de Pernambuco, decidiu formar um "gabinete de assessoria jurídica" voltado tanto à formação de advogados politicamente militantes quanto à defesa dos interesses dos sindicatos trabalhistas, das associações de bairros e das organizações populares no Recife. Tal crítica ao caráter dogmático do curso de bacharelado e tal prática partidário-ideológica do direito não são um fenômeno isolado. No mesmo período, um antigo aluno da pós-graduação da USP, e hoje um dos principais advogados paulistas no combate aos estelionatos do sistema financeiro e aos criminosos de colarinho branco, fazia estas observaçōes num de seus trabalhos acadêmicos:

"O ensino do direito tal como está posto favorece o imobilismo de alunos e professores. Em esforço de renovação, uns atingem o grau de doutrinadores e o prestígio da cadeira universitária. Outros, além do mítico título de "doutor", obtêm a habilitação profissional que lhes permite viver de um trabalho não-braçal. A tarefa do ensino para o aluno é cumprida nestes termos: aprendido o "abc" do processo e do direito civil, já está ele habilitado a viver de inventários e cobranças em maior indagação. Ora, o jurista formado para esta função perde combatividade, sua crítica, sua consciência do papel social do direito. É claro que este operário anônimo do direito é necessário, mas por que deve ser inconsciente? $O$ jurista, convém lembrar, não é apenas advogado: é, também, o juiz que faz parte de um dos poderes políticos do Estado, o Judiciário. Assim, o jurista ocupa a posição de juiz, mas sua preocupação política não terá subido muito mais que a do homem comum, em contraste com a do homem de governo. A alienação do jurista, deste modo, colabora também na supressão das garantias de direitos. É que o centro de equilíbrio social (ou de legitimação) é colocado na eficiência, não no bem do homem. Começa-se a falar num bem comum que só existe nas estatísticas dos planejadores, mas que a pobreza dos centros urbanos desmente. E, em nome desse bem-comum, alcançável pela eficiência, sacrificam-se alguns valores que talvez não fosse inútil preservar".

A menção do juiz, chamando atenção para as implicações políticas de sua função arbitral, também não é gratuita nem se constitui, igualmente, numa opinião isolada. Ela vai de encontro, por exemplo, a um importante e relativamente recente depoimento de um magistrado - não um início de carreira, mas já com o status de desembargador de um Tribunal de Justiça localizado numa região explosiva, na qual se destacam grandes conflitos em torno do direito de propriedade rural. O que nos diz de inédito esse depoimento? 
"para bem interpretar a lei, o juiz não pode ser formalista, dogmático, apegado a formas legais. Interpretar, significa sensibilidade social e postura crítica, além do saber jurídico e dos conhecimentos científicos de que o julgador necessita. Através da visão dialética, eminentemente crítica, o juiz colocase dentro da realidade social e identifica as forças que produzem o direito, para estabelecer a relação entre o direito e a sociedade. Nessa postura, o juiz pode e deve questionar a própria legitimidade da norma, para adequá-la à realidade social. (...) "Comprovado que o direito não é neutro; que a norma legal nem sempre é o ponto de equilíbrio entre interesses conflitantes; que o poder muitas vezes atua em benefício de uns e em detrimento de muitos; que, no Brasil, a maioria constituída das classes trabalhadoras está marginalizada e não tem acesso aos bens da produção - em suma, que a ordem legal é injusta e opressora -, em que consiste a prática libertadora do advogado e função de seu compromisso político? (...). O compromisso político refere-se aos atos da vida pública e particular, e não à atividade política e profissional em si (...). A missão profética do advogado está a nos assegurar que ele é um agente transformador da sociedade, porque a ele é dado denunciar o erro, a injustiça e a opressão; bem como a anunciar a verdade, a justiça e a liberdade (...). Tal postura implica o rompimento com a justiça formal, positivista, baseada no sistema fechado do universo normativo e que ignora as pungentes contradiçōes da vida" (1).

Embora essas afirmações sejam polêmicas, é impossível negá-las como um fato cada vez mais presente em nossa experiência jurídica. A par de suas implicações ideológicas, elas revelam a dificuldade enfrentada pelos juristas de ter de retomar, em novos termos, o velho dilema "hamletiano" do direito, no sentido de pretender ser técnica e ciência ao mesmo tempo. Ou seja: tais depoimentos mostram que não mais se deve confinar o ensino jurídico aos limites estreitos e formalistas de uma estrutura curricular excessivamente dogmática, na qual a autoridade do professor representa a autoridade da lei e o tom da aula magistral permite ao aluno adaptar-se à linguagem da autoridade. Não se trata, é óbvio, de desprezar o conhecimento jurídico especializado, porém de conciliá-lo com um saber genético sobre a produção, a função e as condições de aplicação do direito positivo.

Tal conciliação está a exigir dos cursos jurídicos uma reflexão multidisciplinar capaz de (a) desvendar as relaçōes sociais subjacentes quer às normas quer às relações jurídicas, e (b) fornecer aos estudantes não só métodos de trabalho mais estimulantes e eficazes, mas, igualmente, disciplinas novas e/ou reformuladas. É o caso, por exemplo, da inserção do estudo do direito nas ciên-

(1) Cf. Shelma Lombardi de Kato, in “Revista dos Tribunais”, São Paulo, no 589, novembro de 1984 . 
cias sociais, de maior ênfase à História do Direito, da introdução de Metodologia do Ensino Jurídico e Metodologia do Ensino do Direito como matérias obrigatórias, da revalorização da Filosofia do Direito, especialmente na parte relativa à hermenêutica jurídica, e da análise adensada das relações de natureza complexa (conflitos do tipo "capital x trabalho"; "governo x comunidade"; "produtores x consumidores"). Não se trata de agregar de modo a-sistemático mais disciplinas a um currículo já sobrecarregado, mas de resgatar a própria organicidade do curso. Entre outras razões porque o desafio de um ensino formativo e inter-disciplinar não se limita ao mero relacionamento do direito com a economia, a sociologia, e a ciência política, sendo indispensável valorizar o estudo do direito num marco teórico em condiçōes de oferecer uma perspectiva e crítica dos institutos jurídicos e das relaçōes sócio-econômicas que lhes deram origem e função.

Como efetuar tais mudanças? Como evitar erros recentes, cometidos pelas comissōes do MEC e da OAB nos anos 70, em cujo âmbito muito se falou a respeito da necessidade de uma nova abordagem do direito, limitando as inovaçōes, contudo, a pequenas alterações de carga horária, a desdobramentos de matérias dogmáticas em disciplinas muito técnicas e de interesse muitas vezes restrito? Como impedir que o curso jurídico se limite somente a informar o corpo discente sobre o estado atual da jurisprudência, não o estimulando a identificar e discutir os diferentes modos por meio dos quais vão surgindo esquemas inéditos para problemas não previstos nem pela doutrina nem pelos tribunais? A meu ver, tais mudanças somente poderão ser efetuadas com um mínimo de rigor metodológico se, a partir de uma reflexão mais cuidadosa em torno do tipo de direito ensinado em nossas escolas, formos capazes de discutir sem preconceitos ideológicos a função social do jurista, o caráter instrumental da dogmática jurídica e as influências ideológicas na formação do conhecimento jurídico.

Nessa linha, façamos um rápido exame das diretrizes do atual curso de bacharelado no país, tomando como ponto de referência as "faculdades-padrão", como a FD-USP. Minha primeira tese é a de que a "Ciência do Direito" hoje tida como válida na maioria absoluta de nossos cursos jurídicos não constitui um discurso homogêneo. Pelo contrário, ele reflete a utilização simultânea de vários paradigmas de ciência, os quais são ensinados aos alunos sob o vago e ambíguo rótulo de "humanisno". A idéia de paradigma tem aqui um significado bastante preciso ${ }^{(2)}$, implicando uma teoria básica, uma matriz disciplinar

(2) Cf. Thomas Kuhn, “The structures of scientific revolutions”, Chicago, Chicago University Press, 1970; Boaventura dos Santos, "Da sociologia da ciência à política científica" Coimbra, Boletim da Faculdade de Letras da Universidade de Coimbra, 1977; e José Eduardo Faria "Eficácia Jurídica e violência simbólica", Rio de Janeiro, Forense, 1986. 
e algumas aplicações exemplares, aceitas pelos cientistas ao ponto de suspenderem o esforço crítico de discussão de seus pressupostos e de suas possíveis alternativas substitutivas.

Deste modo, os paradigmas acabam estabelecendo o sentido do limite e o limite do sentido das atividades científicas, de forma que o interesse da ciência se voltaria tanto à resolução dos problemas e à eliminação das incongruências segundo os esquemas teóricos e metodológicos aceitos quanto a uma extensão a questões originariamente não tematizadas no âmbito da aplicação do paradigma. Como tais esquemas teóricos e metodológicos terminam por impor quer a definição dos problemas quer a organização das estratégias da resolução, as discussōes no âmbito das ciências "desenvolvidas" e "maduras" correm o risco de se transformarem em "puzzles" - isto é, enígmas com um número limitado de peças que o cientista, à imagem de um jogador de xadrez, vai movendo até encontrar a solução final.

Tal solução, como ocorre nos enígmas, muitas vezes é conhecida antecipadamente - o que se desconhece, na verdade, são apenas os pormenores de seu conteúdo e do processo para atingir. Isto significa que o paradigma adquirido pelo cientista, no decorrer de sua formação profissional, fornece-lhe as "regras do jogo", descreve-lhe as "peças" com que deve jogar e, por fim, indica-lhe a natureza do resultado a se chegar. Portanto, caso o cientista venha a fracassar nas primeiras tentativas, seus equívocos e dificuldades poderão ser seguramente imputados somente ao seu despreparo e sua inabilidade. As regras fornecidas pelo paradigma jamais são postas em causa - mesmo porque, na ausência delas, não existiria sequer o próprio enígma.

Alguns dos paradigmas hoje prevalecentes em nossos cursos jurídicos são decorrentes de uma cultura tradicional que iniciou seu processo de decadência a partir da expansão industrial dos anos 50 . Eles estão ainda associados a um positivismo transcendente, de acordo com o qual o direito positivo é postulado como um direito natural inerente ao homem, integrante de sua personalidade, motivo pelo qual a lei e a ordem passam a ser os primeiros valores naturais que se deveria preservar. Encarando o direito como um objeto ético, algo que indivíduo encontra na sociedade e por ele se regra, e dando ao ensino um enfoque generalista, privilegiam-se aqui questões relativas à justiça, à legitimidade e aos vínculos entre direito e moral. Outros paradigmas, estes consolidados no decorrer da modernização sócio-econômica do país, estão vinculados ao caráter normativista do positivismo de inspiração kelseniana. Eles consideram o Estado como fonte central de todo o direito e a lei como sua única expressão, formando um sistema fechado e formalmente coerente, cuja pretensão de "completude" despreza como "metajurídicas" todas as indagações de natureza social, política e econômica. Esta abordagem implica a concepção da cultura jurídica como simples repertório de dogmas, propiciando a formulação da "dogmática jurídica" como um mero conjunto de normas. No âmbito da dogmática, em 
síntese, a preocupação central é a subsunção do fato à previsão legal (tipicidade), valorizando-se os aspectos lógico-formais do direito positivo e enfatizando-se as questōes da legalidade, da validez da norma, da determinação do significado das regras, da integração das lacunas, da eliminação de antinomias etc.

Embora ambos os paradigmas sejam encontrados em nossas faculdades de direito, eles não se situam numa posição de igualdade - o que nem sempre é percebido à primeira vista, face a permanente ambigüidade das relações do saber jurídico com o social, ambigüidade essa obscurecida pelo ideal monolítico de uma ciência do direito hegemônica. No conflito histórico entre esses dois paradigmas, cada vez mais o positivismo normativista vai invadindo o espaço ocupado pelo positivismo transcendente, incorporando-o apenas com o objetivo de utilizá-lo de maneira estereotipada como justificativa retórica da legitimidade de seus pressupostos lógicos e de suas prescrições formais. Em outras palavras, à medida que o positivismo normativista avança tanto em nossas faculdades de direito quanto no próprio universo profissional dos juristas, no limite ele se vale de uma vulgata jusnaturalista - expressa sob a forma da defesa de um vago e ambíguo "humanismo" - para invocar a validade de sua função social.

Esse processo de "apropriação" de um paradigma pelo outro é bastante sutil. Ele decorre do progressivo consenso dos juristas em torno não propriamente de uma mesma teoria geral do direito, mas sim da vontade de se eliminar a discussão de questões básicas sobre o objeto e o saber jurídico, como via para maior concentração das atividades ditas "científicas" na sua tarefa específica de construção sistemática. Ao estabelecer o consenso em torno do monopólio da força assumida pelo Estado e ao condicionar os modos de pensar dos juristas, o positivismo normativista tende assim a se constituir no que Kuhn chama de "ciência madura": o momento em que o único paradigma atinge sua plenitude e seu apogeu, impedindo os cientistas de tomar parte de discussões intermináveis acerca dos pressupostos fundamentais, enfrentando problemas "improdutivos" ou "insolúveis" e polemizando com os "dissidentes" ou "contestadores".

A "ciência madura" redefine os problemas e as incongruências até então sem resposta, fornecendo-lhes soluções convincentes e estabelecendo as condições de cientificidade do conhecimento produzido no seu âmbito. Enquanto as "ciências imaturas" são as não consolidadas, coexistindo com diferentes modos de atendimento do trabalho científico, todos sem condições de reivindicar para si, de maneira excludente, o monopólio do tipo de saber dotado de autoridade própria e capaz de servir como base para o progresso da ciência, as "ciências maduras" são aquelas cujos princípios e regras em hipótese alguma são postas em causa, exprimindo uma profunda adesão dos cientistas ao paradigma. Como a crença é a de que os problemas fundamentais foram definitivamente resolvidos pelo paradigma, as "ciências maduras" inexoravelmente tendem a cristali- 
zar-se sobre si mesmas, privilegiando a investigação rotineira e burocratizada e entreabrindo uma situação de resistência às mudanças ou às críticas e de isolamento disciplinar. No limite, pois, a "maturidade" da ciência se converte em sinônimo de recusa ao avanço, às inovações, à criatividade e mesmo às críticas. Entre as conseqüências fundamentais da progressiva hegemonia do positivismo normativista, enquanto princípio paradigmático constitutivo dos cursos jurídicos do país, está a de que o direito pode ser todo ensinado se forem transmitidas as premissas básicas do sistema. As funções criativas e especulativas são relegadas à categoria de matérias introdutórias, cuja função é menos a de "formar" os alunos e mais de informá-los de maneira estereotipada e padronizada sobre a linguagem necessária ao aprendizado da dogmática. À teoria do Estado, por exemplo, caberia a responsabilidade de fornecer os "topoi" do direito público; à economia, os "topoi" para o direito comercial; ao direito romano, os "topoi" do direito privado, etc. À medida que as matérias "introdutórias" revelam-se incapazes de dar organicidade ao curso, o elenco de disciplinas assim estudado faz com que o direito apareça para o estudante como uma série de dados sem vinculação entre si. Além do mais, os institutos jurídicos não são apresentados com referência aos problemas concretos que os geraram, mas sim como soluçōes definitivas em conformidade com as leis vigentes.

Trata-se, em suma, apenas de transmitir uma informação de caráter meramente instrumental - o conjunto dos dogmas do direito, que abrirá as portas de todas as câmaras do "kafkiniano" castelo legal. Mas uma informação truncada e descontínua, uma vez que o ordenamento jurídico é apreendido somente em suas partes constitutivas, sem uma visão orgânica do conjunto e sem que a maioria dos alunos tenha uma concepção global do que ocorre. Com o passar do tempo, portanto, a ausência de raciocínio crítico e problematizante termina por cristalizar ẹ esclerosar um conhecimento jurídico crescentemente setorializado em múltiplas áreas de especialização, impedindo por completo sua adaptação às novas situações sociais.

"Como saber de autoridade, afirma um crítico do positivismo normativista, a ciência jurídica reproduz em sua estrutura interna as exigências próprias de sua função na sociedade. Sua dimensão essencialmente prática, dirigida ao controle social, à integração dos conflitos que à distribuição de autoridade, reflete-se internamente num fortalecimento da função autoritária de seu paradigma e matrizes disciplinares. Os resultados da ciência jurídica são, além de produtos da comunidade científica, instâncias portadoras de uma pretensão de vinculatoriedade com relação à comunidade política. Na medida em que a teoria positivista do ordenamento supõe os postulados da plenitude hermética, produzse uma redução à unidade de todas as autoridades possíveis, com a conseqüente determinação de uma via também única de indicação e prescrição. A função so- 
cial do direito condiciona, assim, a natureza e as funções do paradigma científico hegemônico"(3).

Decorre daí inflexibilidade e a imobilidade da estrutura atual dos cursos jurídicos, em nome da segurança da lei, condenando os estudantes a uma (in)formação burocrática e algo subserviente, incapaz de perceber e captar os novos pontos de conflito e tensão social, mas capaz de versar o bacharel em retórica e prolixidades. Isso sem falar no fato de que as obras de base da dogmática jurídica, ainda hoje utilizadas nos cursos de graduação, começaram a ser produzidas a partir da segunda metade do século XIX, na transição do historicismo para o positivismo, estimulada por meio dos trabalhos de Savigny e thering, no caso do direito privado, e de Jellinek e Kelsen, no âmbito do direito público - todos, portanto, antes da crise dos anos 30, a qual, como é sabido, deflagra um processo de "publicização" do direito privado e de "administrativização" do direito público, face ao papel cada vez mais regulador do Executivo, esvaziando princípios tradicionais e gerando institutos jurídicos novos e originais.

Desta maneira, as faculdades de direito foram limitadas a simples "escolas de legalidade", por meio das quais são reproduzidas soluções pré-elaboradas a partir de casos exemplares. Isso permite (a) que se resguarde acriticamente determinadas opiniões tidas como "juízos científicos", e (b) que, graças a um saber pretensamente "humanista" e supostamente não-ideológico, com a falsa aparência de um conhecimento sistemático e coerente, sejam transmitidas as crenças que sustentam a dogmática jurídica. Ao forjar uma mentalidade estritamente legalista em progressiva contradição com uma realidade crescentemente não-legalista, em cujo âmbito a "racionalidade" material cada vez mais se sobrepõe à "racionalidade formal", esse tipo de "ciência" praticado em nossos cursos de direito reduz o saber normativo a um estereotipado "senso comum teórico dos juristas de ofício"(4).

(3) "O que outorga à moderna ciência do direito o caráter da dogmática é precisamente o estabelecimento de certos pressupostos de índole diversa, afirmados com uma pretensão de validez prévia a toda justificação estritamente científica (...) Esta afirmação dogmática acompanha e fortalece o processo de institucionalização da ciência e seu conteúdo principal é não tanto o que resulta de seu aspecto afirmativo - a proposta teórica e metodológica da ciência jurídica cultivada pelo historicismo e consolidada pelo positivismo - como seu aspecto negativo - referido no que se exclui do âmbito legítimo da investigação científica". Cf. Enrique Zuleta Puceiro, "Teoria Jurídica y Crisis de Legitimación", Buenos Aires, Anuário de Filosofia Política y Jurídica, 1982, pp. 294-296.

4 Cf. Luís Alberto Warat, "El sentido comum teórico", in contradogmáticas, Florianopolis, Associaçáo Latino-Americana de Metodologia do Ensino Jurídico, nº 1, 1981. 
Essa expressão traduz um complexo porém contraditório conjunto de crenças, juízos éticos, proposiçōes científicas, pontos de vista hegemônicos e justificações, expresso por meio de disciplinas específicas legitimadas mediante discursos produzidos pelos órgãos institucionais e cristalizadas pelas práticas jurídicas inerentes a esses órgãos. Ao consolidar um conhecimento tendo em vista sua finalidade prática e imediata, instaurando uma racionalidade meramente formal e abrindo espaço para um discurso mítico, o "senso comum teórico" implica uma saturação ideológica no conhecimento do direito, um fechamento na possibilidade de discussōes epistemológicas, uma inércia reflexiva, a falta de interesse na reforma social, o conformismo dos satisfeitos, a ausência de crítica por parte tanto de alunos quanto de professores e um impedimente para a mudança da própria problemática jurídica. $\mathrm{O}$ "senso comum teórico" não tem, assim, a pretensão de construir um objeto de conhecimento sobre a realidade social; ele visa, apenas, a normatizá-la e justificá-la por meio de um conhecimento padronizado.

Um ensino ao nível do "senso comum teórico", tal como é praticado entre nós, termina por atribuir significaçōes discutíveis e arbitrárias da realidade social, projetando-as imaginariamente como possíveis e desejáveis, ainda que nem sempre factíveis, plasmando-as em discursos reificantes, a-históricos e com pretensões de generalidade e universalidade. Em vez de apresentar institutos jurídicos como formas de soluções de conflitos com raízes no processo das relações sociais, valoriza-se quase que exclusivamente uma abordagem sistemática e lógico-dedutiva, privilegiando-se o princípio da autoridade - isto é, a opinião dos "preclaros mestres" e "insígnes doutores", todos citados aos borbotões como pretexto para demonstração de uma erudição sem peso teórico, recheando manuais e livros - isto quando não servindo para engrossar teses acadêmicas de professores pouco criativos e sem inspiração, abrindo caminho para que o "pedantismo da ligeireza" sirva de critério para o prevalecimento, no âmbito do corpo docente, de um tipo modal de mestre acrítico, burocrático e subserviente aos clichês predominantes entre os juristas de ofício.

Mediante tal senso comum teórico produz-se, então, um "circular reasoning", ou seja: conjunto de discursos aparentemente unitários, porém de cientificidade duvidosa. Estes, provocando certos efeitos de realidade e coerência, conseguem configurar a história de maneira idealizada, com a finalidade de reproduzir formas sociais hegemônicas. Ao buscar a conciliação aparente e retórica das contradições sociais, o "senso comum teórico" projeta-as numa dimensão harmoniosa de relações e esquemas ideais e práticos, homogeneizando valores sociais e jurídicos, silenciando o papel social e histórico do direito, proporcionando os lugares-comuns para o raciocínio jurídico, etc. $O$ problema, no entanto, é que a realidade social, tal como se nos apresenta está longé de ser harmoniosa, linear e progressiva - na verdade, ela é articulada e conformada significativamente por diferenças dialéticas. 
Minha segunda tese é a de que os novos objetivos e as eventuais reformas que porventura vierem a ser definidas não podem ser limitadas a uma simples instância didática. De um lado porque, pela sua própria natureza, o ensino do direito jamais deve ser reduzido a um mero elenco de disciplinas de natureza exclusivamente técnica e profissionalizante. De outro porque, como afirmam Passeron e Bourdieu, todo ato pedagógico é um processo de violência simbólica em que se impõe um arbitrário cultural voltado à reprodução de uma determinada estrutura das relaçōes de classe. Conforme suas palavras,

"Toda ação pedagógica é objetivamente uma violência sirnbólica enquanto imposição, por um poder arbitrário, de um arbitrário cultural. (...) Todo poder de violência simbólica, isto é, todo poder que chega a impor significação e a impô-las como legítimas, dissimulando as relações de força que estão na base de sua força, acrescenta sua própria força, isto é, propriamente simbólica, a essas relaçōes de força". (...) Todo sistema de ensino institucionalizado deve as características específicas de sua estrutura e de seu funcionamento ao fato de que lhe é preciso produzir e reproduzir, pelos meios próprios da instituição, as condições institucionais cuja existência e persistência (auto-reprodução da instituição). São necessários tanto ao exercício de sua função própria de inculcação quanto à realização de sua função de reprodução de uma arbitrária cultura da qual ele não é o produtor (reprodução cultural) e cuja reprodução contribui à reprodução das relações entre os grupos ou as classes (reprodução social)" (5).

Isso significa que ensinar o direito é, também, uma forma de se ensinar a encarar e acatar o direito. Ou seja: de aceitar, mediante um sutil processo de dissimulação, reprodução e justificação ideológica, os valores, os conceitos e as categorias que correspondem a uma formação social e política específica. "A neutralidade proclamada relativamente aos credos éticos e políticos, ou mesmo a hostilidade apregoada para com os poderes -escrevem esses autores a respeito da universidade laica e liberal, em cujo âmbito a dogmática jurídica encontrou acolhida privilegiada- torna menos suspeitável a contribuição que o sistema de ensino é o único capaz de prestar à manutenção da ordem estabelecida". A ilusão de um ensino neutro, concluem, "é tanto mais perniciosa pelo fato de que a recusa ostensiva da função de doutrinamento ou, pelo menos, das formas mais declaradas da propaganda política e a instrução cívica pode preencher... uma função ideológica ao dissimular a função da legitimação da ordem social"(().

5 Cf. Jean Claude Passeron e Pierre Bourdieu, "A reprodução: elementos para uma teoria do sistema de ensino", São Paulo, Francisco Alves, 1975, pp. 19-20 e 24.

6 Idem, ibidem, pp. 214-218. 
Decorre daí a necessidade de se fortalecer as disciplinas destinadas a propiciar uma análise abrangente e crítica de suas relaçōes com o sistema social existente. Com que objetivo? Com a finalidade de permitir um controle metodológico e epistemológico mais rigoroso do que as faculdades de direito produzem ao pretender ensinar um saber simultaneamente "humanístico" e "profissionalizante", a fim de que os corpos docente e discente possam recusar o papel de objetos passivos a que têm sido condenados por um conservadorismo pedagógico cujo objetivo maior é o de manter-se intocado ao lado do conservadorismo sócio-econômico e político-jurídico.

Com o fortalecimento dessas disciplinas não se pretende, pois, racionalizar a transmissão de conteúdos dogmáticos, nem criar ilusoriamente a aparência de problematização no âmbito do ensino jurídico, reduzindo o "cases system" a meros "puzzles". Pretende-se, sim, tanto estimular a discussão sobre as questões determinantes das interpretações jurídicas e das decisões judiciais quanto preparar os estudantes à reflexão e à dúvida metódica. Mesmo porque, se é certo que toda atividade acadêmica e científica pressupōe uma teoria que estabeleça seus parâmetros básicos, e se é correto que quer as teorias quer as técnicas de investigação e de ensino a elas correspondentes vinculam-se às perspectivas sócio-econômicas e político-culturais dos vários grupos sociais, refletindo assim (embora de maneira indireta) seus interesses específicos e extra-científicos, jamais haverá educação nem pesquisa que possam ser consideradas "neutras". Daí a importância de uma permanente vigilância epistemológica e de uma crítica metodológica capaz de propiciar contra-leituras das normas jurídicas e das próprias doutrinas sobre o direito positivo.

Sem esse tipo de preparação, os estudantes estarão condenados a viver frustrados no universo político jurídico. Em outras palavras, continuarão enfrentando dificuldades para compreender as crescentes relações sociais que não se submetem aos rígidos e esquemáticos padrōes pseudos analíticos do "senso comum teórico". O risco é o de que, a exemplo dos juízes, promotores, procuradores e advogados hoje matriculados por cursos de pós-graduação, eles também terminem por receber somente informações a respeito de institutos jurídicos vinculados a situações e contextos desaparecidos ou em fase de desaparecimento. Conseqüentemente, a terminarem a faculdade, terão a amargura de descobrir o descompasso entre a (in)formação profissional recebida e o universo de conflitos reais, não tendo assim preparo teórico e prático suficientes para reordenar seus conceitos e ajustar-se a uma realidade nova e responsável por inúmeras transformações nas funções do direito. No caso específico da FDUSP, o corpo discente - ao menos seus segmentos mais dinâmicos na graduação e pós-graduação - já começa a se mobilizar para a reivindicação de aulas destinadas a habilitá-los na compreensão das razões pelas quais, por exemplo,

(I) as funções do direito têm sido alteradas na mesma proporção em que as relaçōes sociais se tornam mais complexas, evoluindo de simples instrumentos de controle social para agir como instrumento de direção social, valendo-se 
de estratégias de socialização, integração, atomização, trivialização e repressão para dispersar as contradiçóes sociais e os conflitos que elas suscitam, mantendo-os em níveis de tensão funcionalmente compatíveis com a ordem política vigente.

(II) o Judiciário, na medida em que se encontrava despreparado para resolver conflitos de natureza coletiva e classista, aos poucos vai substituindo a relação formal entre o homem abstrato (o "sujeito de direito"), a lei geral-abstrata e o juiz meramente técnico e exegeta por uma relação material - quando não dialética - entre os homens concretos, a "lei do processo de concretização" e o magistrado criador, participante e consciente de que a credibilidade da instituição por ele representada depende do reconhecimento da justiça material e de permanente atualização histórica e sociológica do direito positivo;

(III) o direito civil, enquanto pilar do direito privado, não conseguiu desapegar-se da noção de propriedade estática e personalíssima;

(IV) o direito público se mostra desorientado em matéria de controle monetário, financeiro, fiscal, ao mesmo tempo em que a reiterada afirmação das liberdades públicas e dos direitos individuais, por parte de nossas Constituições, não tem sido garantia de sua efetividade na vida da Nação;

(V) a segurança jurídica continua atrelada à concepção de indivíduo enlaçado por outro indivíduo ou pelo Estado (mas visto como pessoa), ignorando a existência tanto do Estado burocratizado, despersonalizado e onipotente quanto da grande empresa e dos grupos econômicos, etc;

(VI) as sucessivas invasões de terras urbanas ou rurais vão crescentemente desafiando os tribunais, bem como comprometendo a coerência das decisões judiciais e administrativas, com os ocupantes socorrendo-se do próprio direito que lhes nega a propriedade para "politizando" a questão, tentar legalizar uma situação de fato e assim criar novos direitos; e

(VII) os debates sobre a reforma do judiciário têm aberto caminho para a elaboração de aternativas ao modelo central, formal e profissionalizado que, a partir do movimento codificador do século XIX, vem dominando a administração da justiça processual - alternativas essas relativas à criação de procedimentos, instâncias e instituiçōes relativamente descentralizadas, quando não informais e mesmo desprofissionalizadas, em condições de oferecer soluções mais rápidas, baratas e acessíveis ao processamento de litígios.

Nesse sentido, oito ordens de questões podem ser levantadas para ilustrar a falta de operacionalidade da dogmática jurídica num contexto como o atual. São elas:

(I) o problema dos contratos e do princípio "rebus sic stantibus" numa sociedade caracterizada pela rapidez das transformaçōes e pela intensidade das contradições e seu impacto na estrutura econômica do país;

(II) o rompimento de vários princípios básicos do direito constitucional historicamente consolidados, como os da legalidade, da constitucionalidade das leis e da anualidade dos tributos, sem o acompanhamento da eficência e da co- 
ordenação governamental sempre invocada para justificar o sacrifício daqueles dogmas;

(III) a não abrangência das classes desfavorecidas pelas instituições de direito, na medida em que a marginalização sócio-econômica também produz a marginalização jurídica;

(IV) a emergência de formas novas e mais eficazes de controle e ordenação social, com a gradativa substituição dos mecanismos normativos de repressão por mecanismos de prevenção, mediante uma progressiva combinatória entre técnicas de estímulo e desencorajamento, de natureza persuasivạ, com normas tradicionais, de caráter protetor-repressivo. Tal processo de mudança vem abrindo caminho para que certos autores -como Norberto Bobbio- têm chamado de "controles antecipados", ampliando a níveis imaginados pelo liberalismo jurídico as possibilidades de intervenção do poder estatal no domínio privado e rompendo com uma ortodoxia conceitual baseada em distinções dicotômicas do tipo público/privado, Estado/sociedade civil, política/economia, etc.

(V) a crescente incapacidade de adaptação da racionalidade formal a uma engenharia social baseada numa regulação cada vez mais particularística flexível e fragmentária, cujo caráter "neocorporativo" reflete o modo pelo qual classes e frações de classes dominantes vão compondo soluções institucionais negociadas nos diferentes "anéis burocráticos" do aparelho estatal;

(VI) a crescente percepção de que, no lado do monopólio da violência legítima por parte do Estado, aspecto esse tão valorizados pela concepção liberal do poder jurídico-político, há também um poder difuso, sem centro, atomizado, móvel, múltiplo - o poder inerente às relaçōes e às interações sociais, presente na familia, na fábrica, na escola, na igreja, etc., burocratizando a vida social, aprisionando o cotidiano, contendo os desejos, calibrando as expectativas, disciplinando reações, estabelecendo interditos e cultivando a "alquimia" do dever, isto é, da conduta "responsável".

(VII) as novas lutas sociais desenvolvidas a partir de reivindicações de caráter legal evendenciam, de modo cada vez mais intenso, as funções regulamentares do Estado; elas demonstram como o direito, ao ordenar as relaçöes sociais e dar ao sistema social um mínimo de segurança, ao mesmo tempo em que tenta trivializar conflitos e dispersar tensões, também acaba provocando problemas inéditos para os quais não há respostas possíveis dentro da ordem jurídica, entreabrindo a necessidade de negociações políticas; e estas, por sua vez, não apenas tendem a disseminar a disfuncionalidade dos princípos gerais do direito, como, ainda a abrir novos espaços para ação política dos grupos interessados numa reformulação estrutural das instituições de direito; $\mathrm{e}$

(VIII) o advento de experiências jurídicas alternativas, decorrentes da progressiva substituição da "racionalidade formal" pela "racionalidade material", propiciando a "informalização da justiça", os esforços de "justiça comunitárias" e mesmo por inúmeras campanhas em favor da "deslegalização" de certos comportamentos hoje excessivamente regulados pelo direito positivo. 
Todas essas questōes são intrincadas demais para serem aqui aprofundadas. Elas constituem aspectos específicos das transformaçōes do papel do direito e do Estado numa sociedade tão cambiante como a nossa, exigindo assim um modelo analítico capaz de integrá-las a um quadro conceitual em condições de superar os obstáculos epistemológicos ao progresso do conhecimento jurídico, basicamente decorrentes da distinção Estado/sociedade civil - o que não pode ser objeto deste artigo. Por ora, o que importa, a partir dessas questões, é chamar atenção para a complexa articulação estrutural das formas explíticas e difusas de controle e direção social em sociedades bastante estratificadas, como a brasileira.

Nessas sociedades, as tensões e os conflitos sociais obrigam o Estado a constantes ajustamentos e mudanças no processo de organização sócio-econômica e dominação política sem, no entanto, superar as contradições em que tal organização e tal dominação assentam. Esse processo de ajustamento e mudança tem ampliado a diversificação interna das formas jurídicas e das estruturas normativas e institucionais em que elas operam, entreabrindo deste modo o caráter assimétrico, heterogêneo e fragmentário dos padrōes de sociabilidade, controle e direção inerentes ao funcionamento das sociedades de classes. Todavia, a teoria política e jurídica liberal, da qual o positivismo normativista é sua grande expressão, recusa-se a reconhecer esse caráter, reduzindo a questão do direito e da denominação a um bloco monolítico constituído pelo poder jurídico-político do Estado. "Nesta redução, afirma Boaventura dos Santos, um dos responsáveis pela renovaçāo do ensino jurídico na Universidade de Coimbra, reside o fundamento da distinção entre o Estado e a sociedade civil, nos termos da qual o Estado é o domínio do poder enquanto a sociedade civil é o domínio da liberdade".

"A crise profunda que esta teoria atravessa, diz ele, está relacionada com as transformações recentes no processo de acumulação capitalista. A elas se ligam as reformas que temos vindo a analisar, as quais, por sua vez, se ligam a outras reformas de perfil semelhante noutras áreas da vida social. A proliferação destas reformas poderá acarretar mudanças na natureza do poder estatal (cósmico) e, particularmente, no âmbito das suas relações com o poder caósmico emergente das relações sociais da sociedade civil. Na medida em que o Estado, ao informalizar a justiça, tenta cooptar o poder coercitivo produzido no desenrolar das 'relações sociais continuadas', está a articular explicitamente o seu poder cósmico com o poder caósmico que até agora fora mantido fora do seu alcance. Na medida em que o Estado consegue, por esta via, controlar ações e relações sociais dificilmente reguláveis por processos jurídicos formais e integrar todo o universo social dos litígios decorrentes dessas açōes e relações no processamento informal, o Estado está de fato a expandir-se. E expande-se através de um processo que na superfíeie da estrutura social surge como um processo de retratação. $\mathrm{O}$ que parece ser deslegalização é na verdade relegalização. Por outras palavras, o Estado está-se a expandir sob forma de sociedade 
civil. E se assim for, a dicotomia Estado/sociedade civil deixa de ter utilidade térica, se é que alguma vez teve. E porque o Estado se expande na forma de sociedade civil, o controle social pode ser executado sob a forma de participação social, a violência, sob a forma de consenso, a dominação de classe, sob a forma de açẳo comunitária. Em suma, o poder do Estado expande-se através de um 'governo indireto'. Desta maneira, os processos 'nativos' da sociedade civil, as interações, os contextos e ambiências que constituem o tecido da ação social são integrados na estratégia global da dominação política capitalista. Â superfície das reformas no domínio da informalização da justiça tal integração é negada (escondida pela subcodificação possibilitada pelo uso extensivo da retória jurídica, a qual, como é sabido, mobiliza o conhecimento do senso comum e a linguagem ordinária) ${ }^{(7)}$.

Em síntese, a ausência de uma efetiva discussão de problemas como esses, no âmbito de nossas faculdades de direito, mostra que elas não têm dado aos alunos o instrumental teórico e analítico para a compreensão de seu mundo circundante. Revela, também, que a formação "humanística" sempre invocada pela maioria dos professores ainda permanece presa a uma retórica tradicional, a qual, por sua vez, não explica nem as contradições nem os antagonismos da sociedade urbanizada e de massas em que vivemos. Tal formação tende a transformar-se num simples "verniz", isto é, brilhante mas superficial, não habilitando os juristas de amanhã a agirem realmente em função dos imperativos sociais inerentes a uma realidade em permanente transformação.

7 Cf. Boaventura dos Santos, "Law and Community: the politics of informal of state power in late capitalism", in "The politics of informal justice", Richard Abel organizador, New York, Academic Press, 1982. 